\title{
Cluster analysis to evaluate chemical compounds in the waters of piezometers from a drilling wastes landfill
}

\author{
Justyna Kujawska*,1, and Wojciech $\mathrm{Cel}^{1}$ \\ ${ }^{1}$ Institute of Renewable Energy Engineering, Lublin University of Technology, 40B Nadbystrzycka Street, Lublin, Poland
}

\begin{abstract}
Storage of drilling wastes threatens the natural environment. Cluster analysis was employed for evaluation of the behaviour of chemical compounds in the water of piezometers from the drilling waste management facility in Luchów. Cluster analysis proved to be an efficient method, enabling the identification of groups of chemical compounds threatening the environment.
\end{abstract}

\section{Introduction}

The economic development of counties undergoes a rapid increase, the production of goods and services grows significantly, whereas the global population has doubled [1]. Hence, the consumption of energy and natural resources has increased as well. New sources of energy are constantly being sought. The prospecting of gas from both the conventional and unconventional sources gains increasing attention. Finding the balance between the economic development and the natural environment becomes a necessity. In order to improve the energy use efficiency, environmental protection and achieve the sustainable development, new legal regulations pertaining to efficient use of environment are being devised [2].

Poland is a country with high expectations regarding shale gas. Extensive works connected with shale gas exploration are being conducted [3]. These works may cause excessive pollution of the environment in the course of exploitation as well as other processes. Drilling yields substantial amounts of waste. New methods of their management are being sought. Additionally, new requirements related to their neutralization, storage, etc. are being devised. In Poland, since 2012, application of drilling waste in the reclamation of landfills and creation of waste treatment facilities was the commonly employed method of its management. The amendment to the Waste Management Act implemented in 2016, restricted filling the mining excavations with mining waste for reclamation and technological purposes. According to the updated regulations, mining wastes, depending on their type, may be stored:

- for up to 6 months - hazardous mining waste, the production of which could not be foreseen;

- for up to 1 year - mining waste other than hazardous or inert;

- for up to 3 years - non-polluted soil, mining waste other than hazardous produced in the course of exploratory works, waste produced during excavation, processing and storage of peat [4].

The properties of drilling waste depend on: the type of rock, drilling fluid, the employed technology. Drilling wastes contain the substances used for the preparation of drilling fluids, technological fluids, as well as the products of their degradation. The chemical compounds originating from drilling fluids found in the drilling wastes include: mineral oils, organic compounds such as: polymers (tannins, lignosulfonates, lignites, xanthan gum, guar gum; starch and cellulose derivatives, active surfactants, inorganic compounds (oxides and hydroxides of calcium, magnesium, sodium, potassium, as well as potassium or sodium chlorides) as well as barite, iron ores, galena, chalk, and limestone. Wastes also contain metal, not only the ones added to drilling fluids, but also originating from sedimentary rocks [5]. The compounds found in drilling wastes may migrate to surface and ground waters, as well as soils and plants [6].

In the case of waste landfills or waste treatment facilities, the main migration pathways include: leachates, surface run-offs as well as emission of gases and dusts. Leachates mainly originate from precipitation waters infiltrating through a landfill, leaching a whole range of pollutants.

Constant monitoring of a waste management facility and landfills is necessary, requiring devising the monitoring programmes. The presented research involved cluster analysis and multidimensional statistical analysis evaluating the behaviour of chemical compounds in the water from piezometers from the waste management facility in Luchów.

Cluster analysis aims at grouping objects into a common cluster. Clustering maximizes the homogeneity of objects belonging to the same groups and maximizes heterogeneity by assigning objects to different groups [7].

Cluster analysis is widely used in environmental engineering for studying the water quality $[8,9]$. Ashley

Corresponding author: j.kujawska@pollub.pl 
and Lloyd (1978) employed cluster analysis for the classification of ground waters depending on the content of organic compounds [10]. Frapporti et al. (1993) carried out cluster analysis of ground waters depending on the type of soils [11]. Cluster analysis was also employed for determination of the flow direction of ground waters on the basis of hydrochemical analyses of water $[12,13]$.

\section{Research methodology}

\subsection{Location}

The studies were carried out at a drilling waste landfill situated in Luchów Górny, a village in Lubelskie Voivodeship, in Biłgorajski county, Poland. Samples of water were collected from the piezometers located in three spots around the landfill. In each spot, there were two piezometers collecting water from different depths (Table 1).

Table 1. Data pertaining to the ground water collection spots.

\begin{tabular}{|c|c|c|c|}
\hline Name & $\begin{array}{c}\text { Altitude } \\
\text { [m] }\end{array}$ & $\begin{array}{l}\text { Depth of a } \\
\text { piezometer } \\
\text { measured } \\
\text { from the } \\
\text { ground level } \\
\text { [m] }\end{array}$ & $\begin{array}{c}\text { Depth of a } \\
\text { table of } \\
\text { water } \\
\text { measured } \\
\text { from the } \\
\text { ground level } \\
\text { [m] } \\
\end{array}$ \\
\hline PC I Q & \multirow{2}{*}{237} & 6.1 & 4.20 \\
\hline PC I T & & 17.0 & 4.40 \\
\hline PC II Q & \multirow{2}{*}{229} & 6.2 & 5.10 \\
\hline PC II T & & 17.5 & 4.90 \\
\hline PC III Q & \multirow{2}{*}{225} & 6.0 & 3.40 \\
\hline PC III T & & 16.5 & 3.10 \\
\hline
\end{tabular}

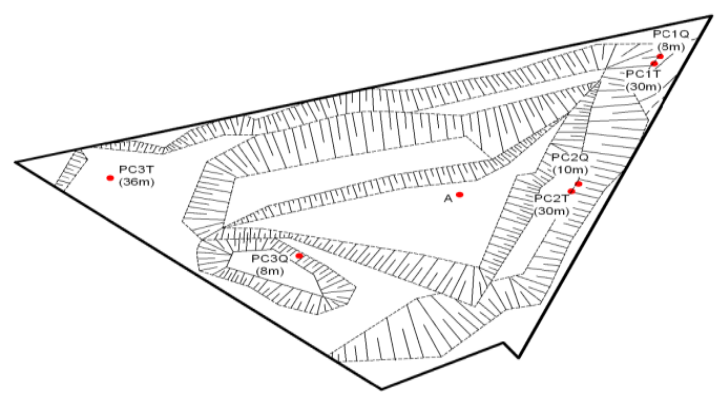

Fig. 1. Location of piezometers on the waste deposition landfill. The depth of piezometers is given in the brackets.

The piezometers marked as PC I are found in the northernmost and highest part of the landfill, which borders with agricultural land. The PC II piezometers are $230 \mathrm{~m}$ southwest from the highest landfill spot and lie in the area which is highly waterlogged. The PC III piezometers are $290 \mathrm{~m}$ west of the highest part of the landfill and are located on the sawmill area. The location of piezometers in relation to the landfill was presented in Fig. 1.

\subsection{Samples collection and preparation}

The samples were collected from March 2015 to December 2015. In total, 21 samples of water were collected.

The samples were taken according to the PN-76/C04620/03 Standard.

\subsection{Scope of research and analytic methods}

The following parameters were determined in the collected samples:

- $\mathrm{pH}$, by means of the potentiometric method, with a multifunctional VERSA STAR meter manufactured by ORION

- specific electrolytic conductivity, by means of a multifunctional VERSA STAR meter manufactured by ORION

- chloride content, with Mohr's method

- content of metals, including: $\mathrm{Al}, \mathrm{B}, \mathrm{Ba}, \mathrm{Cd}, \mathrm{Cr}, \mathrm{K}, \mathrm{Na}$, $\mathrm{Ni}, \mathrm{Pb}$, by means of Inductively Coupled Plasma Optical Emission Spectrometry method, with JY 238 Ultrace (Jobin Yvon-Horriba, France)

- content of organic carbon, by means of TOC-5050A analyzer manufactured by Schimadzu (in line with PNISO 14335 standard)

- content of sulphate ions, determined by means of spectrophotometric method $\mathrm{PBL} / \mathrm{CH} / 28 / 06$, issue 02 of 07.11.2011 on the basis of HACH 8051 method

- chemical oxygen demand was determined with spectrophotometric method, with HACH - LANGE PN - ISO 157520058051

\subsection{Statistical analysis of clusters}

Cluster analysis method was employed for grouping variables by means of Ward's method. Ward's method estimates the distance between clusters using the analysis of variance approach. This method aims at minimizing the sum of squares of deviation within clusters. The chemical properties of waters from piezometers from the waste management facility were used as variables. The analysis was carried out on the basis of Statistica software package (v. 13.1).

\section{Results}

The obtained results were presented in tables 2 and 3 . The concentration of aluminium was below the detection limit; therefore, it was omitted in the statistical studies. The results of cluster analysis were presented in Figure 2 . The cluster analysis enabled to identify three groups of chemical properties of waters. The first one, with the shortest average distance comprises $\mathrm{pH}$, as well as the concentrations of $\mathrm{B}, \mathrm{Ba}, \mathrm{Mn}$, and $\mathrm{Ni}$. The second group includes the values of TOC, the concentration of $\mathrm{Ca}, \mathrm{K}$, $\mathrm{Mg}, \mathrm{Ng}$, chlorides bound with the group comprising the 
concentration of iron and COD. The third one, with the greatest distance between the identified groups, involves the values of conductivity, TDS and the concentration of sulphates. The obtained results of analyses were compared with the permissible values determined in the Regulation of the Minister of Environment of 21 December 2015 establishing the criteria for and the way of classifying the state of uniform parts of groundwater [14]. The concentrations of compounds in the examined waters indicate that none of them meet the criteria of border values for the waters of good chemical status. The lowest quality characterized the waters from PC IIIQ piezometer. The permissible values of as many as 8 parameters were exceeded, including: conductivity, TOC, concentrations of $\mathrm{B}, \mathrm{Ca}, \mathrm{Mg}, \mathrm{Mn}, \mathrm{Ni}$ (in all measurements) and $\mathrm{Al}$ (only in March). In the adjacent PC IIIT piezometer, 4 parameters were exceeded: TOC, $\mathrm{B}, \mathrm{Ca}$ (in all measurements) and $\mathrm{Al}$ (in July). Both piezometers were located at a lower height than the others. In the remaining piezometers, only single parameters were exceeded: in PCIT and PCIQ piezometers - TOC, in the case of PCIIT - K, whereas in PCIIQ - Ca.

Table 2. Concentration of metals in the water taken from piezometers.

\begin{tabular}{|c|c|c|c|c|c|c|c|c|c|c|c|}
\hline \multirow[t]{2}{*}{ Piezometer } & \multirow{2}{*}{$\begin{array}{c}\text { Sampling } \\
\text { time }\end{array}$} & Al & B & $\mathbf{B a}$ & $\mathrm{Ca}$ & $\mathbf{F e}$ & $\mathbf{K}$ & Mg & Mn & $\mathbf{N a}$ & $\mathbf{N i}$ \\
\hline & & \multicolumn{10}{|c|}{$\left[\mathrm{mg} / \mathrm{dm}^{3}\right]$} \\
\hline \multirow[t]{3}{*}{ PC I T } & III & $<\mathrm{d} .1$ & 0.90 & 0.036 & 19.44 & 0.09 & 6.01 & 4.38 & 0.01 & 126.54 & $<\mathrm{d} .1$ \\
\hline & VII & $<\mathrm{d} .1$ & 1.09 & 0.035 & 19.71 & 0.03 & 6.46 & 4.81 & 0.015 & 131.58 & $<\mathrm{d} .1$ \\
\hline & $\mathrm{X}$ & $<\mathrm{d} .1$ & 0.98 & 0.03 & 24.45 & $<\mathrm{d} .1$ & 7.23 & 5.39 & 0.02 & 118.74 & $<\mathrm{d} .1$ \\
\hline \multirow[t]{3}{*}{$\begin{array}{l}\text { PC I Q } \\
\end{array}$} & III & $<\mathrm{d} .1$ & $<\mathrm{d} .1$ & 0.03 & 141.47 & 0.11 & 2.61 & 11.88 & 0.03 & 24.2 & $<\mathrm{d} .1$ \\
\hline & VII & $<\mathrm{d} .1$ & $<\mathrm{d} .1$ & 0.04 & 138.65 & 0.14 & 2.69 & 12.98 & 0.04 & 19.99 & $<\mathrm{d} .1$ \\
\hline & $\mathrm{X}$ & $<\mathrm{d} .1$ & $<\mathrm{d} .1$ & 0.03 & 133.54 & $<\mathrm{d} .1$ & 2.99 & 12.87 & 0.01 & 16.57 & $<\mathrm{d} .1$ \\
\hline \multirow[t]{3}{*}{ PC II T } & III & $<\mathrm{d} .1$ & $<\mathrm{d} .1$ & 0.099 & 115.71 & $<\mathrm{d} .1$ & 18.73 & 8.71 & 0.25 & 94.58 & $<\mathrm{d} .1$ \\
\hline & VII & $<\mathrm{d} .1$ & 0.50 & 0.11 & 133.29 & 0.05 & 23.18 & 12.90 & 0.29 & 121.58 & $<\mathrm{d} .1$ \\
\hline & $\mathrm{X}$ & $<\mathrm{d} .1$ & 0.44 & 0.12 & 161.83 & $<\mathrm{d} .1$ & 27.58 & 13.83 & $<\mathrm{d} .1$ & 130.11 & 0.003 \\
\hline \multirow[t]{3}{*}{ PC II Q } & III & $<\mathrm{d} .1$ & $<\mathrm{d} .1$ & 0.05 & 328.62 & 0.24 & 3.70 & 45.46 & 0.09 & 90.57 & $<\mathrm{d} .1$ \\
\hline & VII & $<\mathrm{d} .1$ & 0.14 & 0.062 & 324.06 & 0.23 & 4.07 & 50.01 & 0.16 & 92.53 & $<\mathrm{d} .1$ \\
\hline & $\mathrm{X}$ & 0.99 & 0.18 & 0.07 & 236.96 & 0.33 & 3.09 & 45.26 & 0.18 & 99.01 & 0.004 \\
\hline \multirow[t]{3}{*}{ PC III T } & III & $<\mathrm{d} .1$ & 2.05 & 0.02 & 467.33 & 0 & 3.63 & 99.33 & $<\mathrm{d} .1$ & 35.44 & $<\mathrm{d} .1$ \\
\hline & VII & 4.32 & 2.33 & 0.013 & 466.99 & 0.15 & 4.84 & 99.87 & 0.01 & 33.66 & $<\mathrm{d} .1$ \\
\hline & $\mathrm{X}$ & 0.02 & 2.28 & 0.01 & 445.28 & 0.26 & 4.23 & 88,0 & $<\mathrm{d} .1$ & 32.14 & $<\mathrm{d} .1$ \\
\hline \multirow[t]{3}{*}{ PC III Q } & III & 5.02 & 1.91 & 0.02 & 469.28 & 0 & 11.26 & 120,09 & 1.74 & 24.58 & 0.09 \\
\hline & VII & $<$ d.1. & 2.05 & 0.013 & 500.08 & 0.01 & 13.18 & 116,75 & 1.35 & 22.36 & 0.08 \\
\hline & $\mathrm{X}$ & $<$ d.1. & 1.21 & 0.05 & 414.31 & 0 & 14.20 & 139,22 & 1.62 & 24.58 & 0.07 \\
\hline $\begin{array}{l}\text { Border } \\
\text { values }{ }^{1)}\end{array}$ & & 0.2 & 1 & 0.7 & 200 & 5 & 15 & 100 & 1 & 200 & 0.02 \\
\hline
\end{tabular}

parameters with the values within the standards of Class IV waters (waters of unsatisfactory quality) parameters with the values within the standards of Class $\mathrm{V}$ waters (waters of poor quality) 
Table 3. Characteristics of water collected from piezometers.

\begin{tabular}{|c|c|c|c|c|c|c|c|c|}
\hline \multirow[t]{2}{*}{ Piezometer } & \multirow{2}{*}{$\begin{array}{l}\text { Sampling } \\
\text { time }\end{array}$} & \multirow[t]{2}{*}{ pH } & \multirow{2}{*}{$\begin{array}{c}\text { Conductivity } \\
{[\mu \mathrm{S} / \mathrm{cm}]}\end{array}$} & \multirow{2}{*}{$\begin{array}{c}\text { TDS } \\
{\left[\mathrm{mg} / \mathrm{dm}^{3}\right]}\end{array}$} & \multirow{2}{*}{$\begin{array}{c}\text { TOC } \\
{\left[\mathrm{mgC}^{\left.-\mathrm{dm}^{3}\right]}\right.}\end{array}$} & \multirow{2}{*}{$\begin{array}{c}\text { COD } \\
{\left[\mathrm{mg} / \mathrm{dm}^{3}\right]}\end{array}$} & \multirow{2}{*}{$\begin{array}{c}\text { Chlorides } \\
{\left[\mathrm{mgCl} / \mathrm{dm}^{3}\right]}\end{array}$} & \multirow{2}{*}{$\begin{array}{c}\text { Sulfate } \\
{\left[\mathrm{mgSO}_{4}{ }^{2-}\right.} \\
\left./ \mathrm{dm}^{3}\right] \\
\end{array}$} \\
\hline & & & & & & & & \\
\hline \multirow{3}{*}{ PC I T } & III & 7.9 & 662 & 399 & 17.04 & 20 & 8.65 & 13.1 \\
\hline & VII & 7.6 & 629 & 383.4 & 15.99 & 19.7 & 5.21 & 17.9 \\
\hline & $\mathrm{X}$ & 7.5 & 634 & 388.21 & 16.32 & 25.1 & 8.79 & 13.1 \\
\hline \multirow[t]{3}{*}{ PC I Q } & III & 7.3 & 794 & 468.65 & 18.26 & 32 & 54.02 & 59.5 \\
\hline & VII & 7.2 & 723 & 439.80 & 16.25 & 31.3 & 52.06 & 62.3 \\
\hline & $\mathrm{X}$ & 7.6 & 789 & 476.43 & 15.49 & 35.8 & 58.10 & 56.1 \\
\hline \multirow[t]{3}{*}{ PC II T } & III & 7.9 & 669 & 399.05 & 8.66 & 35.6 & 70.56 & 63.9 \\
\hline & VII & 8.1 & 689 & 416.41 & 8.57 & 34.7 & 80.35 & 198 \\
\hline & $\mathrm{X}$ & 7.7 & 658 & 392.45 & 8.36 & 39.2 & 77.54 & 98.4 \\
\hline \multirow[t]{3}{*}{ PC II Q } & III & 6.5 & 1058 & 667.27 & 6.06 & 39.5 & 129.03 & 68.8 \\
\hline & VII & 6.3 & 1122 & 639.58 & 5.99 & 38.4 & 104.56 & 140 \\
\hline & $\mathrm{X}$ & 6.4 & 1010 & 664.87 & 6.02 & 42.9 & 119.30 & 264 \\
\hline \multirow[t]{3}{*}{ PC III T } & III & 6.3 & 2030 & 1230 & 20.12 & 20.2 & 49.50 & 1222 \\
\hline & VII & 6.2 & 2045 & 1239 & 22.03 & 18.1 & 55.60 & 1100 \\
\hline & $\mathrm{X}$ & 6.9 & 2033 & 1230 & 21.77 & 22.7 & 53.11 & 1278 \\
\hline \multirow[t]{3}{*}{ PC III Q } & III & 6.9 & 2628 & 1626 & 15.48 & 22.58 & 10.89 & 1929 \\
\hline & VII & 6.0 & 2731 & 1682.44 & 17.23 & 23.1 & 11.02 & 1128 \\
\hline & $\mathrm{X}$ & 6.1 & 2654 & 1601.41 & 17.03 & 27.5 & 7.02 & 1152 \\
\hline $\begin{array}{l}\text { Border } \\
\text { values }{ }^{1)}\end{array}$ & & $\begin{array}{l}6.5- \\
9.5\end{array}$ & 2500 & $\begin{array}{c}\text { Not } \\
\text { defined }\end{array}$ & 10 & $\begin{array}{c}\text { Not } \\
\text { defined }\end{array}$ & 250 & 250 \\
\hline
\end{tabular}

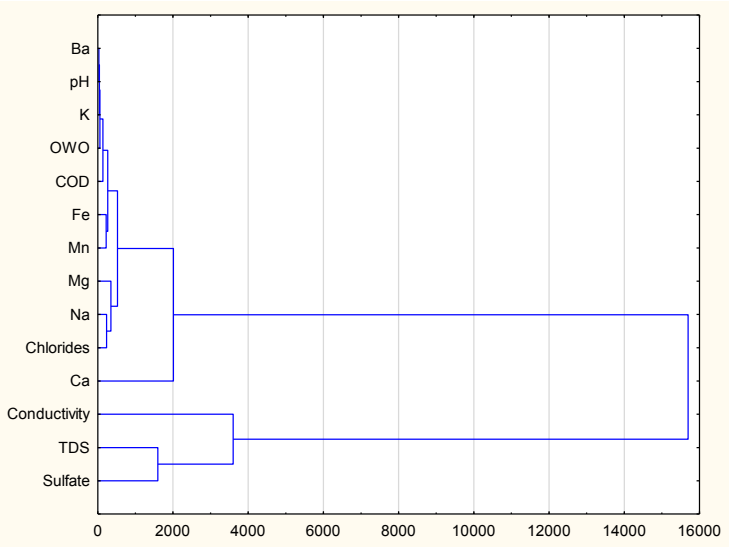

Fig. 2. Cluster analysis of selected parameters of water from piezometers from the waste management facility.
The obtained research results of water samples from piezometers indicate the elevated content of the compounds from the groups characterized by medium and greatest distance in the conducted cluster analysis. This confirms the applicability of cluster analysis for grouping the pollutants present in the ground waters.

\section{Conclusion}

The conducted cluster analysis involved classification of 21 water samples into three groups (low, medium and high pollution) on the basis of the chemical compounds in their content.

The results of cluster analysis may be used for optimizing the water quality monitoring programme, and enable to decrease the frequency of water sample 
collection. In other words, in the further studies, the number of spots for monitoring the water quality may be reduced by selecting only the compounds which threaten the natural environment.

The results of statistical analyses allow to select the high-priority areas, thus aiding in the management of ground water quality.

\section{References}

1. A. Duda, J. Gołębiowska, A. Żelazna, Probl Ekorozw 11, 1 (2016)

2. P. Rydzewski , Probl Ekorozw 11, 1 (2016)

3. J. Macuda., M. Bogacki, J. Siemek., Probl Ekorozw 12, 1 (2016)

4. PolishWaste Management Act Dz.U. 2008 nr 138 poz. 865

5. J.M. Neff, Integr Environ Asses 4, 2 (2014)

6. Y.Y. Fan, Wang G.C., Fu J.H., Zheng X.-H., Pet Sci Technol 32 (2014)
7. S. Javadi, S.M. Hashemy, K. Mohammadi, K.W.F. Howard, J Hydrol 549 (2017)

8. M. Hajigholizadeh, A. M. Melesse, Catena 151 (2017)

9. W. de Souza Pereira, G. Ferrari de Morais, D. de Azevedo Py Júnior, International Nuclear Atlantic Conference (INAC 2011 Belo Horizonte, MG, Brazil)

10. R.P. Ashley, J.W. Lloyd, J. Hydrol. 39 (1978)

11. G. Frapporti, P. Vriend, P.F.M. Van Gaans, Water Resour. Res. 29, 9 (1993)

12. J.A. Riley, R.K. Steinhorst, G.V. Winter, R.E. Williams, J. Hydrol. 119 (1990).

13. K.M. Ochsenkuhn,, J. Kontoyannakos, M. Ochsenku, J. Hydrol. 194, 1, (1997).

14. Regulation of the Polish Minister of Environment of 21 December 2015 